\title{
Fire Properties of Novel Cellulosic Material Modified with Expandable Graphite
}

\author{
Anielkis S.R. Batista, Wojciech L. Grześkowiak and Bartlomiej Mazela \\ Faculty of Wood Technology, Poznan University of Life Sciences, Wojska Polskiego 38/42, 60637 \\ Poznan, Poland, e-mail: anielkis.batista@up.poznan.pl,wojciech.grzeskowiak@up.poznan.pl, \\ bartlomiej.mazela@up.poznan.pl
}

\begin{abstract}
Expandable graphite (EG) is an intumescent additive known to improve fire properties of various materials. Intumescent fire retardant (IFR) based on $E G$ is a protection method for flammable materials taking the attention of researchers in the past few years (Xie et al., 2000). New studies indicate that EG is a good source of carbonization agent for effective and environmentally friendly intumescent systems (Feng et al. 2013). Although EG is used in a growing number of IFR systems as a blowing agent that will suppress flammable gases up to $75 \%$, while reducing the flame spread index, its application to cellulosic material is not so popular in the cellulose industry today (Krassowski et al., 2012). The current study focuses on flammability, concerning cellulose modified material (CMM).

The objective of this work was CMM encrusted with EG. The general aim of the research was to determine its basic fire resistance properties. The scope of the research included measurement of the following parameters: time to ignition $\left(T_{i}\right)$, time to flame out $\left(T_{f}\right)$, total heat peak (THR) and mass loss (ML). Samples of CMM sheets were manufactured with the use of hydropulper and rapid-koethen devices. Two types of EG (i.e. ES20 C200 and ES100 C10) were used. Sodra Black Cellulose fibres $\left(700 \mathrm{~kg} / \mathrm{N}^{3}\right)$ was used in this experiment. Cellulose milling time was $30 \mathrm{~min}$. and drying time of 40 min. The drying temperature of the final sheets was controlled and kept at $93^{\circ} \mathrm{C}$ to avoid graphite activation. Final sheets were conditioned at room temperature at $20^{\circ} \mathrm{C}$ and relative humidity $60 \%$. With heat flux of $35 \mathrm{~kW} / \mathrm{m}^{2}$, all samples were tested on MLC apparatus. The addition of EG was found to increase the flame retardant effectiveness of cellulosic material. Although $T_{i}$ for all CMM species were lower than that of control samples, this fact actually favored the promotion of char forming, which led to a longer combustion process for all CMM.
\end{abstract}

Keywords: Mass Loss Calorimeter, Char, Expandable Graphite Cellulose, Flammability.

\section{Introduction}

Fire retardant formulation (FRF) based on expandable graphite (EG) is a fire reinforcement method for flammable materials taking the attention of researchers in the past few years (Xie and $\mathrm{Qu}, 2000$ ). As a carbon-layered crystal, EG consists of sheets of carbon atoms strongly bound to each other (Kruger, 2017). The literature indicates that EG is a good source of carbonization agent for effective design of environmentally friendly intumescent systems (Feng et al., 2013). There are insufficient detailed reports in literature on the behaviour of EGintumescent fire retardants (IFR) systems concerning cellulosic materials. Although EG is used in a growing number of IFR systems as a blowing agent that will suppress flammable gases up to $75 \%$, while reducing the flame spread index, its application to cellulosic material is not so popular in the cellulose industry today. Depending on the processing methods, fire retardants (FR) are often categorized as: Additive or non-inert compounds. Additive FRs are often mixed inside the matrix of the polymer during its processing. These FR are usually inert 
to de polymer. Reactive FRs are dose polymerized with a resin during processing of cellulosic material to become integrated into its molecular network structure. These FRs are also known as chemically modified FRs (Jesbains et al., 2011). The footprints of fire retardants points to an effective ideal fire retardant that should be thermo-stable, compact with the protected polymer, should not change the physical-chemical properties of the protected polymer, and have low toxicity under heat exposure or during burning (Camino and Costa, 1987). In order to understand the dynamics of fire retardants it is required to have detailed knowledge of the mechanism of the thermal-degradation progress related to the polymer.

Inventions related to EG are usually linked to its thermal properties, therefore related to reducing the flammability and/or combustibility. In fact, the use of expandable graphite as part of flame retardant agents and fire protection is being promoted by laws and regulations that push the prohibitions of halogenated based fire retardants due to environmental concerns related to the emission of toxic gases from the thermal degradation of halogenated base flame retardants. The European Union is one of the organizations promoting the development of new halogen-free flame retardants (Acuna et al., 2019). EG is a novel product in use in various inventions. Many patents claim that EG properties can be used for diverse of applications. Not only in the field of fire retardants where EG is used to protect fibrous materials, but also in electrical applications. As solid composite, EG was used in lithium/Sulphur batteries as cathode; the solid composite comprised of up to $75 \mathrm{wt}-\%$ of expanded graphite (Schmidt et al., 2017). Rubber melded body material with enhanced fire resistance. In this rubber composition, one of the main components was EG (Sakai and Nakano, 2019). EG is also used in devices of
heat resistance, EG was installed as a retentio
multi-porous materia. with an average pore
allows EG to acconm odate other chemical composites, it has been found to improve the con

From the exfoliation process of expandable graphite, we can obtain a good electrically

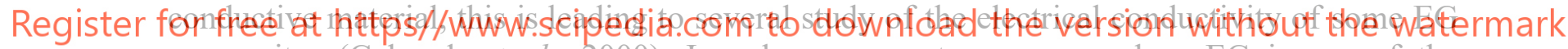
composites (Celzard, et al., 2000). In solar energy storage researches, EG is one of the materials that can enhance the thermal conductivity of solar cell. In the works of Xiao et al., (2013), sodium nitrate, potassium nitrate and their solution were used as the base material. The conductivity of the based material was of about $10 \mathrm{wt} . \%$. With the addition of expanded graphite that has high thermal conductivity, the conductivity of the final material increased at about 40\%. In his work, Xiao et al., (2013) agreed that the theoretical results and the experimental results are in agreement. It is clear that the novel product has a diversity of fields/research areas to contribute with its property in this literature review we consider that the thermal conductivity properties and the potentially electrical conductivity properties are at the top potential characteristics that researchers at observing. Most articles do not address the aesthetic aspect of their final product. When combining EG with other additives the appearance of the final product is not so attractive the final application, especially when it is related to coatings fire retardants formulations. Other concern is related to cost of EG. The market to this product is growing at a fast speed. According to the Markets and Markets (2019), the global graphite market is projected to reach 29.05 billion dollars by 2022 . This is a considerable amount that indicates that the global market is interested on these eco-friendly products. In the academy it is conclusive that the use of EG will increase as novel products 
are developed.

To achieve this goal, the present preliminary experiment will use Mass Loss Calorimeter (MLC) infer the thermal stability of the CMM. MLC is frequently used to explore flammability properties of different type of materials, delivering a suitable sort of technical data (Krassowski et al., 2012). Recent analysis of thermal stability of lingo-cellulosic materials under controlled conditions showed the decomposition temperatures $\left(\mathrm{T}_{\mathrm{d}}\right)$ for lignin, hemicelluloses and cellulose. This last component, with $\mathrm{T}_{\mathrm{d}}=320^{\circ} \mathrm{C}$, char $6 \%$ by mass (Mazela et al., 2018; Fox et al., 2012). The current study focuses on flammability concerning cellulose component only.

The objective of this work was cellulose-based model material (CMM) encrusted with expandable graphite (EG). The general aim of the research was to determine its basic fire resistance properties. The scope of the research involved measurement of the following parameters: time to ignition (Ti), time to flame out (Tf), total heat release peak (THR) and mass loss (ML).

\section{Methods}

Samples of cellulose sheets were manufactured with the use of hydropulper and RapidKoethen devices. Cellulose sheets were encrusted with two types of EG (ES100 C10 and ES20 C200). EG was dispersed in a cellulose pulp at the preparation stage. ES20 C200 had higher amount of fine-grained fraction $(90 \%<75 \mu \mathrm{m})$ and thus was characterized by lower expansion volume $(20 \mathrm{ml} / \mathrm{g})$ in comparison to ES100 C10 type. Three variants of cellulose

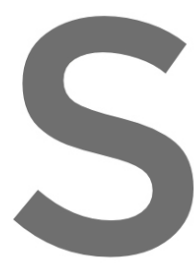
sheets were prepared: contro ES200 C20 or ES100 dimensions of fibers: sheets manufacture. minutes. The drying ten
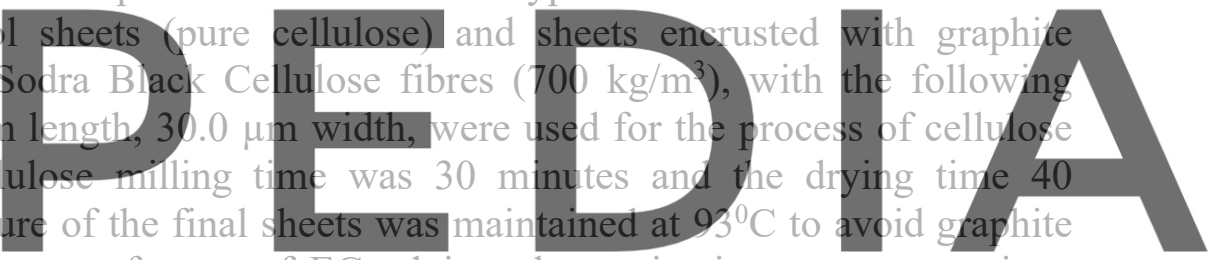
atration notwithstanding the manufacture of EG advises that activation temperature is at

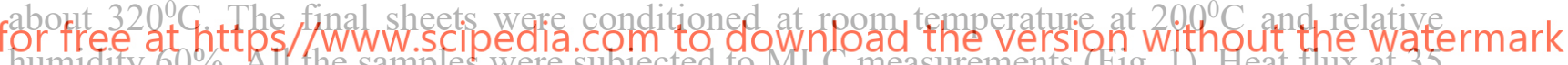
humidity $60 \%$. All the samples were subjected to MLC measurements (Fig. 1). Heat flux at $\mathrm{kW} / \mathrm{m}^{2}$ was estimated as suitable level for all tested samples. This work inferred conclusions on flammability properties of CMM by measuring time to ignition (Ti), time to flame out (Tf), total heat release peak (THR) and mass loss (ML). It was possible to account for all important aspect mentioned above however it was not possible to account for repeatability the samples. This led to some discrepancy in some sample properties (i.e. thickness) as shown on table 1. bellow. 
Table 1. Characterization of samples.

\begin{tabular}{llllll}
\hline Samples & Thickness & THR $\left(\mathrm{MJ} / \mathrm{m}^{2}\right)$ & $\mathrm{T}_{\mathrm{i}}(\mathrm{s})$ & $\mathrm{T}_{\mathrm{f}}(\mathrm{s})$ & THR peak $(\mathrm{MJ} / \mathrm{m})$ \\
\hline Cellulose 01 & 0.89 & 9 & 25 & 94 & 230.72 \\
Cellulose 02 & 0.88 & 7.2 & 21 & 79 & 222.41 \\
Cellulose 03 & 0.89 & 8.3 & 24 & 89 & 236.05 \\
EG200-01 & 1.45 & 6.7 & 22 & 100 & 98.03 \\
EG200-02 & 1.4 & 6 & 21 & 102 & 89.55 \\
\hline EG200-03 & 1.4 & 6 & 20 & 99 & 97.61 \\
EG100-01 & 1.4 & 4.4 & 19 & 108 & 73.32 \\
EG100-02 & 1.5 & 4.4 & 19 & 107 & 75.42 \\
EG100-03 & 1.4 & 4.8 & 19 & 123 & 74.96 \\
\hline
\end{tabular}

It is clear that the mass $(\mathrm{g})$ of each sample are not the same. With the standard deviation calculated to be 0.1 for cellulose samples, 0.5 for EG200 and 0.3 for EG100.
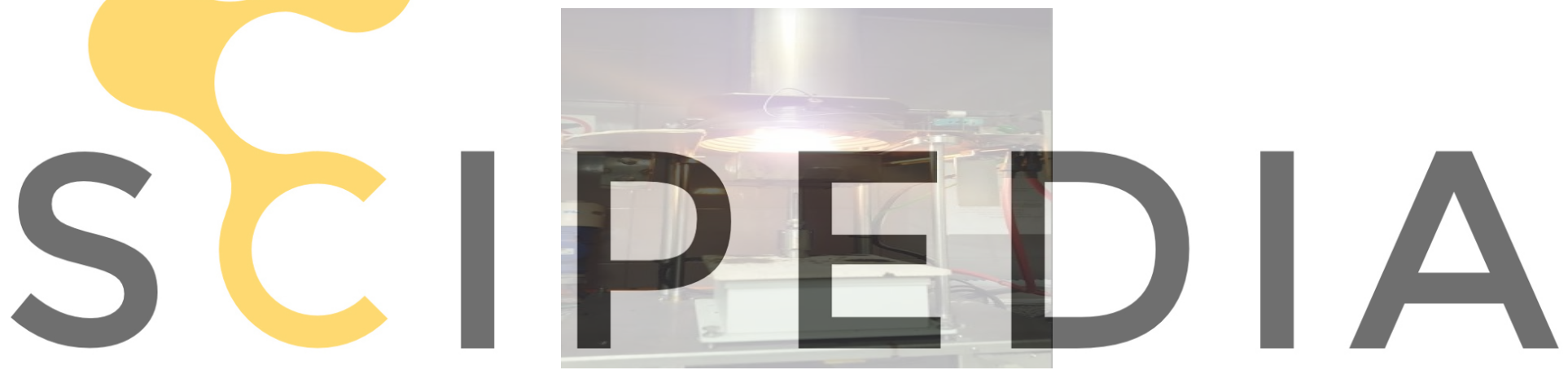

Register for free at https//www.scipedia.com to download the version without the watermark 3 Results

$\mathrm{T}_{\mathrm{i}}$ for CMM encrusted with ES100 C10 and ES20 C200 was estimated at the average on 19.0 and 21.0s respectively. This corresponds to $\mathrm{T}_{\mathrm{i}}$ of ES100 C10 2s faster than that of ES20 C200, while for control samples it was estimated on $23.3 \mathrm{~s}$, control samples resisted $22 \%$ more time than the more "fragile" sample (ES100 C10). As we can confirm in the figure 2 . In average, $T_{i}$ for CMM encrusted with ES100 C10 and ES20 C200 were observed to ignite $4.3 \mathrm{~s}$ and $2.3 \mathrm{~s}$, respectively faster than control samples.

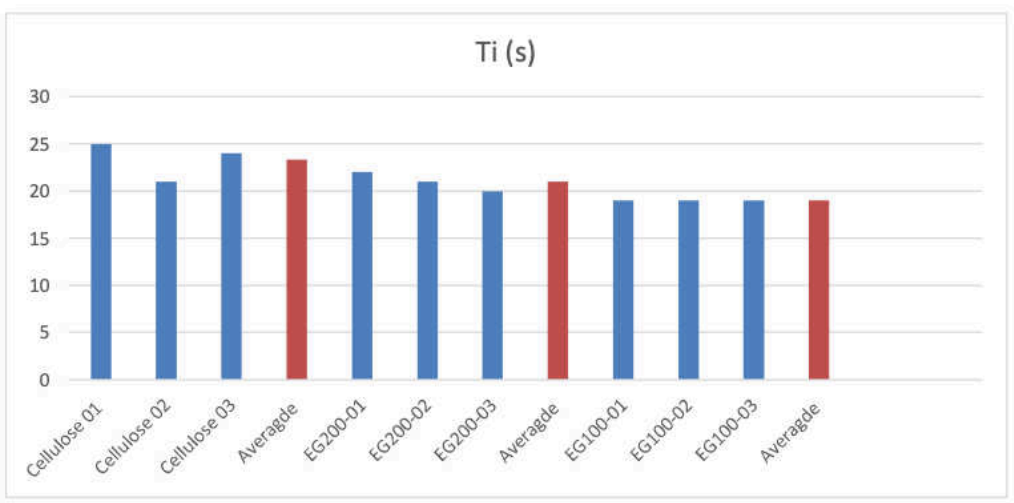

Figure 2. Time to ignition of all samples. 
Figure 3. shows among others, the average $\mathrm{T}_{\mathrm{f}}$ value for CMM encrusted with ES100 C10 was112.7 s, while pure cellulose and CMM with ES20 C200 did register an average of 87.7 and $108.0 \mathrm{~s}$, respectively. In this case however, ES100 C10 showed a resilient behaviour, taking 28\% more time to terminate its combustion process. ES100 C10 showed earlier char formation, this fact can help on fire protection properties.
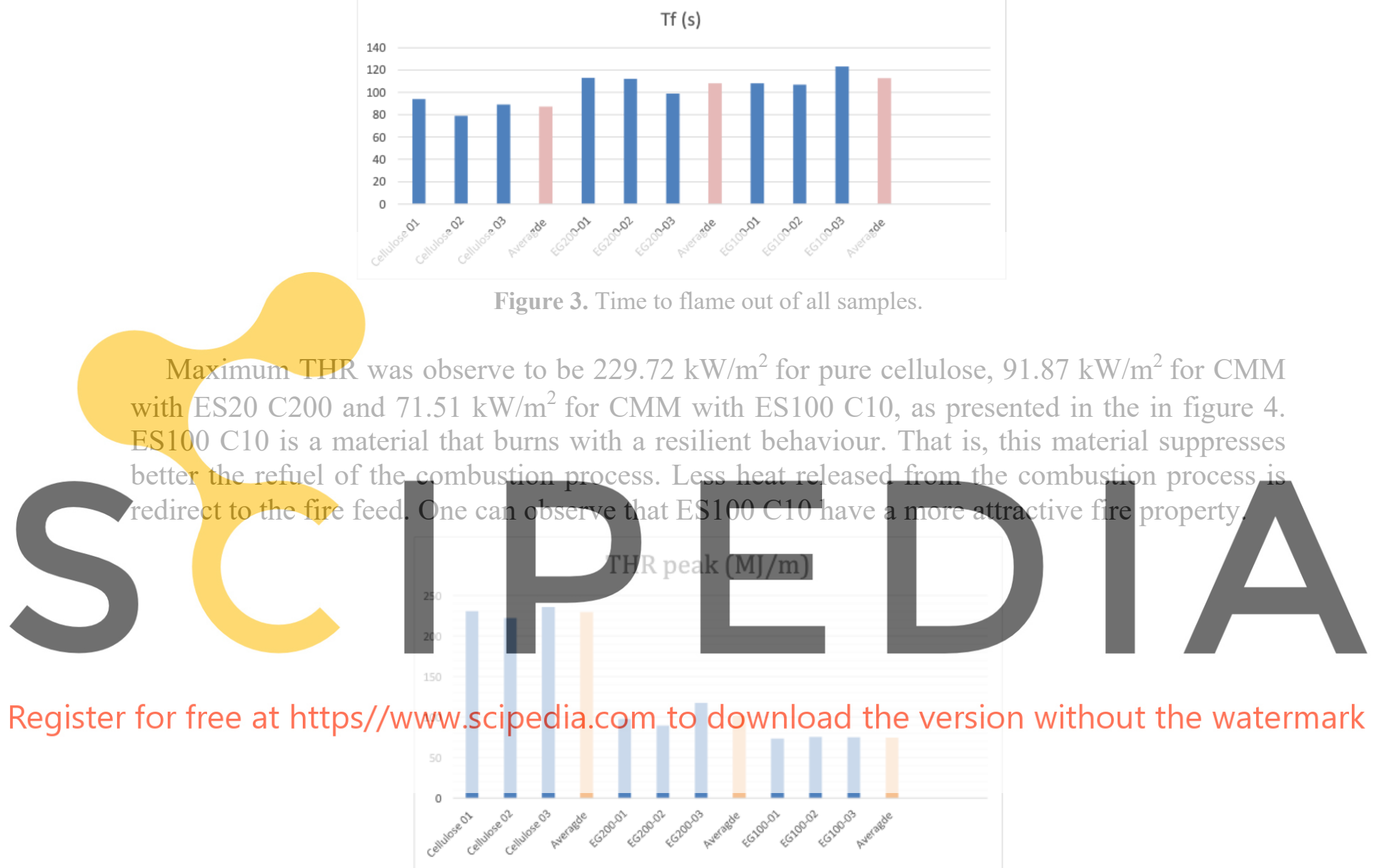

Figure 4. Time to flame out of all samples.

\section{Conclusions}

- The addition of EG was found to increase the flame-retardant effectiveness of cellulosic material.

- Although Ti for all CMM species were lower than for control samples, this fact actually favored the promotion of char forming. The improved physical characteristics of char is achieved by increasing the amount of the insulated layer and reducing crack formation. This aspect allowed the combustion process of CMM with ES100C10, to be $25 \mathrm{~s}$ longer than combustion process of pure cellulose and almost $5 \mathrm{~s}$ longer than that of CMM with ES20 C200. In addition, the maximum HRR for CMM with ES100C10 was 69\% smaller than its compared value for pure cellulose and 22\% smaller than its compared value for CMM with ES20 C200.

- CMM with ES100 C10 is consequently the best performing system in terms of the observed parameters. 


\section{Acknowledgements}

The work was financially supported by the Ministry of Science and Higher Education as the Project No 507.423.09. with subsidies for maintaining the research capacity and the paper was partially financed within the framework of Ministry of Science and Higher Education programme "Regional Initiative of Excellence' in years 2019-2022, Project NO. 005/RID/2018/19". Part of the above mentioned results were also presented on two scientific conferences in year 2019: INPAP 2019 - The future of papermaking, 10-12th of June, Augustów Poland and Wood Science Economy - International scientific conference, 21-22nd of October Poznan, Poland.

\section{ORCID}

Anielkis S.R. Batista: https://orcid.org/0000-0003-1765-1072

Wojciech Ł. Grześkowiak: https://orcid.org/0000-0002-6781-8187

Bartłomiej Mazela: https://orcid.org/0000-0003-0138-3034

\section{References}

Acuña, P., Li, Z., Santiago-Calvo, M., Villafañe, F., Rodríguez-Perez, M.Á. and Wang, D.Y. (2019). Influence of the Characteristics of Expandable Graphite on the Morphology, Thermal Properties, Fire Behaviour and Compression Performance of a Rigid Polyurethane Foam. Polymers, 11(1), 168. doi:10.3390/polym11010168.

Camino, G. and Costa, L. (1987). Performance and Mechanism of Fire Retardants in Polymers-A Review. Polymer degradation and stability, 20, 271-294.

Celzard, A., Marêché, J., Furdin, G. and Puricelli, S. (2000). Electrical conductivity of anisotropic expanded graphite-based monoliths, Journal of Physics D: Applied Physics. doi: 33. 3094. 10.1088/0022-3727/33/23/313.

Feng, C., Zhang, Y., Lang, D., Liu, S., Chi, Z. and Xu, J. (2013). Flame Retardant Mechanism of a Novel Intumescent Flame Retardant Polypropylenc. Procedia Engineering, 52, 97-104.
G, D.M., Lee, J., Zammarano, J., Katsoulis, D., Eldred, D.V., Haverhals, M.L., Trulove, P.C., DeLong, H.C.Aand
Carbohydrate Polymers, 88(3), 847-858.
bains, K., Faiz, A., Megat-Yusoff, P and Ulah, S. (2011). The Study of Bonding Mechanism of Expandable
Graphite based Intumescent Coating 15. Research Journat Of Chemistry And Enviromment.

Flame Retardant Resin. GrafTech International Holdings Inc.

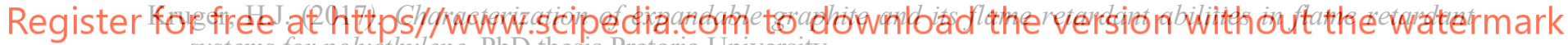
systems for polyethylene. PhD thesis Pretoria University

Mazela, B., Perdoch, W., Grześkowiak, W. and Batista, A. (2018). Selection of heat flux value for wood fire retardants testing using MiLC, IRG-WP doc. No.18-40846.

Murata, T. and Koga, Y. (2019). US2019/0093599 A1.

Sakai, T. and Nakano, S. (2019). US 2019/0225785A1.

Schmidt, R., Panchenko, A., Ewald, B., Hanefeld, P., Sorin, I., Moehwald, H. and Kovalev I., (2017). US 9,577,243 B2.

Xiao, X., Zhang, P. and Li, M. (2013). Thermal characterization of nitrates and nitrates/expanded graphite mixture phase change materials for solar energy storage. Energy Conversion and Management, ISSN 0196- 8904, doi.org/10.1016/j.enconman.2013.04.007.

Xie, R. and Qu, B. (2000). Synergistic effects of expandable graphite with some halogen-free flame-retardants in polyolefin blends. Polymer Degradation and Stability, 71(3), 375-380. 